\title{
Biologics in Psoriasis: Updated Perspectives on Long-Term Safety and Risk Management
}

\author{
A Al-Janabi ${ }^{1,2}$ \\ ZZN Yiu ${ }^{1,2}$
}

'Division of Musculoskeletal and Dermatological Sciences, School of Biological Sciences, Faculty of Biology, Medicine and Health, The University of Manchester, Manchester, UK;

${ }^{2}$ The Dermatology Centre, Salford Royal NHS Foundation Trust, Manchester NIHR Biomedical Research Centre, Manchester Academic Health Science Centre, Manchester, M6 8HD, UK
Correspondence: ZZN Yiu Dermatology Centre, Salford Royal Hospital, Stott Lane, Manchester, M6 8HD, UK

Email zenas.yiu@manchester.ac.uk

\begin{abstract}
Biologics targeting Th1/Th17 cytokines have revolutionised psoriasis treatment. In addition to treatment effectiveness, it is important to define and understand the long-term risks of biologic therapy in order to guide therapy selection and minimise these risks for patients where possible. This review article summarises available evidence from trial data, observational studies and pharmacovigilance registries to explore key long-term risks of biologic treatment, and how these risks might be managed in clinical practice.
\end{abstract}

Keywords: psoriasis, biologics, therapeutics, safety

\section{Introduction}

Psoriasis is a chronic, inflammatory skin disease with a global prevalence of up to $2 \% .{ }^{1}$ It presents with well-defined, red, scaly plaques that can be pruritic or painful and is associated with comorbidities including psoriatic arthritis, hypertension, obesity and diabetes. ${ }^{2-7}$ Psoriatic inflammation is primarily T-helper (Th)17 and Th1-driven, and is mediated by cytokines such as tumour necrosis factor (TNF)- $\alpha$, interleukin (IL)-17 and IL-23. ${ }^{8-11}$ Systemic treatment options for severe psoriasis include broadly-acting oral immunomodulators, such as methotrexate and ciclosporin, and biologics, which are monoclonal immunoglobulin-G (IgG) molecules (with the exception of etanercept) targeting specific cytokines or receptors involved in psoriasis pathogenesis (Table 1).

While Phase III trials are crucial in providing evidence for efficacy and safety of therapies, primary outcome measures in psoriasis are usually efficacy endpoints by 12 or 16 weeks. Trial extensions do not typically include comparator arms, and trials usually exclude participants with significant comorbidities who may be at greater risk of adverse events. ${ }^{24}$ Furthermore, there may be a significant lag time between drug exposure and development of adverse events such as cancer.

This review summarises available trial and observational data for key long-term risks of biologic therapy in psoriasis, and strategies that can be used to minimize risk to patients (Table 2). For the purpose of this article, long-term is defined as 12 months or longer following initiation of therapy.

\section{Infection}

Infection is one of the main causes of biologic discontinuation. ${ }^{25}$ Trial data for adalimumab showed an infectious adverse event incidence of 1.2 events per patient-year compared with 0.8 for placebo participants. ${ }^{12}$ For risankizumab, combined trial data showed the proportion of patients developing infection was 19-24\%, compared with 9 
Table I Summary of Unique Biologic Therapies Licensed for Plaque Psoriasis

\begin{tabular}{|c|c|c|c|c|c|}
\hline Biologic & Structure & Target & Standard Dosing & $\begin{array}{l}\text { Average } \\
\text { Half Life }\end{array}$ & $\begin{array}{l}\text { Efficacy (Trial Primary } \\
\text { Endpoint) at Standard } \\
\text { Dose }\end{array}$ \\
\hline Adalimumab & Human $\lg G \mid \kappa$ & TNF- $\alpha$ & $\begin{array}{l}\text { Loading dose } 80 \mathrm{mg} ; 40 \mathrm{mg} \text { every } 2 \\
\text { weeks }\end{array}$ & 14 days & $71 \%$ PASI-75 at week $16 .{ }^{12}$ \\
\hline $\begin{array}{l}\text { Certolizumab } \\
\text { pegol }\end{array}$ & $\begin{array}{l}\text { PEGylated fab } \\
\text { fragment of } \\
\text { humanized lgGI }\end{array}$ & TNF- $\alpha$ & $\begin{array}{l}400 \mathrm{mg} \text { weeks } 0,2 \text { and } 4 \text {, then } 200 \mathrm{mg} \\
\text { every } 2 \text { weeks. }\end{array}$ & 14 days & $76.7 \%$ PASI-75 at week $16^{13}$ \\
\hline Etanercept & $\begin{array}{l}\text { TNFR and IgG Fc } \\
\text { fusion protein }\end{array}$ & TNF- $\alpha$ & $50 \mathrm{mg}$ weekly & 3 days & $34 \%$ PASI-75 at week $12 . .^{14}$ \\
\hline Infliximab & $\begin{array}{l}\text { Human-murine } \\
\text { chimeric } \lg G I\end{array}$ & TNF- $\alpha$ & $\begin{array}{l}5 \mathrm{mg} / \mathrm{kg} \text { at weeks } 0,2 \text { and } 6 \text {, then every } 8 \\
\text { weeks }\end{array}$ & $\begin{array}{l}8-9.5 \\
\text { days }\end{array}$ & $89 \%$ PASI-75 at week $10 .{ }^{15}$ \\
\hline Secukinumab & Human $\lg G \mid \kappa$ & IL-I7A & $300 \mathrm{mg}$ weeks $\mathrm{I}-5$, then $300 \mathrm{mg}$ monthly. & 27 days & 81.6\% PASI-75 at week $12 .{ }^{16}$ \\
\hline Ixekizumab & Humanized lgG4 & IL-7A & $\begin{array}{l}160 \mathrm{mg} \text { week } 0,80 \mathrm{mg} \text { at weeks } 2,4,6,8 \\
10 \text { and } 12, \text { then } 80 \mathrm{mg} \text { every } 4 \text { weeks }\end{array}$ & 13 days & 82.6\% PASI-75 at week $12 .{ }^{17}$ \\
\hline Brodalumab & Human $\lg G 2$ & IL-I7RA & $\begin{array}{l}210 \mathrm{mg} \text { weeks } 0,1 \text { and } 2 \text {, then every } 2 \\
\text { weeks }\end{array}$ & II days & $86 \%$ PASI-75 at week $12 .^{18}$ \\
\hline Bimekizumab & Humanized lgGI & $\begin{array}{l}\text { IL-I7A, IL-I7F, } \\
\text { IL-I7AF }\end{array}$ & $\begin{array}{l}320 \mathrm{mg} \text { weeks } 0,4,8,12,16 \text { then every } 8 \\
\text { weeks }\end{array}$ & 23 days & $91 \%$ PASI-90 at week $16 .{ }^{19}$ \\
\hline Ustekinumab & Human $\lg G \mid \kappa$ & $\begin{array}{l}\text { P40 subunit of } \\
\text { IL- } 12 \text { and } \\
\text { IL-23 }\end{array}$ & $\begin{array}{l}45 \mathrm{mg} \text { weeks } 0 \text { and } 4 \text {, then every } 12 \\
\text { weeks }\end{array}$ & 21 days & $67 \%$ PASI-75 at week $12 .{ }^{20}$ \\
\hline Guselkumab & Human $\lg G \mid \lambda$ & $\begin{array}{l}\text { Pl9 subunit of } \\
\text { IL-23 }\end{array}$ & $\begin{array}{l}100 \mathrm{mg} \text { weeks } 0 \text { and } 4 \text {, then every } 8 \\
\text { weeks }\end{array}$ & $\begin{array}{l}15-18 \\
\text { days }\end{array}$ & $70 \%$ PASI-90 at week $16^{21}$ \\
\hline Risankizumab & Humanized IgGI & $\begin{array}{l}\text { PI9 subunit of } \\
\text { IL-23 }\end{array}$ & $\begin{array}{l}150 \mathrm{mg} \text { weeks } 0 \text { and } 4 \text {, then every } 12 \\
\text { weeks }\end{array}$ & $\begin{array}{l}28-29 \\
\text { days }\end{array}$ & $75 \%$ PASI-90 at week $16 .{ }^{22}$ \\
\hline Tildrakizumab & Humanized $\lg G \mid \kappa$ & $\begin{array}{l}\text { Pl9 subunit of } \\
\text { IL-23 }\end{array}$ & $\begin{array}{l}100 \mathrm{mg} \text { weeks } 0 \text { and } 4 \text {, then every } 12 \\
\text { weeks }\end{array}$ & 23.4 days & $64 \%$ PASI-75 at week $12 .{ }^{23}$ \\
\hline
\end{tabular}

Abbreviations: IgG, immunoglobulin-G; PASI-75, 75\% reduction in psoriasis area severity index (PASI); PASI-90, 90\% reduction in PASI.

$16 \%$ for placebo. ${ }^{22}$ However, different trials have different safety outcome measures and do not necessarily include longterm data, and are not powered to study particular adverse events of interest such as serious infections.

\section{Serious Infections}

Serious infection is defined as those requiring intravenous antibiotics or resulting in hospitalization or death. A systematic review and meta-analysis (pre-print) of 29,724 psoriasis clinical trial participants found a low rate of serious infection ( $\mathrm{n}=97)$ at $10-16$ weeks with no statistically significant difference at 10-16 weeks when compared with placebo or each other. ${ }^{26}$ Strengths of this study included a large combined sample size and exclusion of studies where the majority of participants were being treated primarily for psoriatic arthritis. While the data are reassuring, trial participants may not be representative of real-world populations and observational data also need to be considered.

One study of 9038 participants, with a median followup time of 2 years, from the British Association of Dermatologists Biologics and Immunomodulators Register (BADBIR) compared serious infection risk in patients receiving etanercept, adalimumab or ustekinumab with non-biologic systemic treatments, and found no significant difference in risk between each other. ${ }^{27}$ Another study utilising BADBIR found an increased risk of serious infection on infliximab with an incidence rate (IR) of 47.8 per 1000 person-years $(95 \%$ confidence interval [CI] 
Table 2 Adverse Events of Interest Caused by Biologics Used for Psoriasis and Risk Management Strategies

\begin{tabular}{|c|c|c|}
\hline Adverse Event Type & Summary & Risk Management Strategies \\
\hline \multicolumn{3}{|l|}{ Infections } \\
\hline Serious infections & $\begin{array}{l}\text { Increased risk with infliximab and lower risk with } \\
\text { ustekinumab in observational studies. }\end{array}$ & $\begin{array}{l}\text { Consider avoiding infliximab in patients at high risk of } \\
\text { infection }\end{array}$ \\
\hline Fungal infections & $\begin{array}{l}\text { Trial data suggests candida infection in all anti-ILI } 7 \text { agents, } \\
\text { particularly bimekizumab }\end{array}$ & $\begin{array}{l}\text { Consider alternative biologic classes in patients where } \\
\text { avoiding candida infection is a priority }\end{array}$ \\
\hline Tuberculosis & $\begin{array}{l}\text { Increased odds of developing TB on anti-TNFs in meta- } \\
\text { analysis of rheumatoid arthritis trials. No reactivation in } 31 \\
\text { risankizumab-treated patients with latent TB }\end{array}$ & $\begin{array}{l}\text { Screen for TB with interferon gamma release assay prior } \\
\text { to initiation of biologic therapy. Treat latent TB prior to } \\
\text { biologic initiation. Consider risankizumab if psoriasis } \\
\text { treatment required before anti-TB therapy. }\end{array}$ \\
\hline $\begin{array}{l}\text { Post-operative } \\
\text { infections }\end{array}$ & Lack of data on post-operative risk in psoriasis patients. & $\begin{array}{l}\text { Case-by-case consideration on whether to pause biologic } \\
\text { therapy, or whether to time surgery prior to next dose of } \\
\text { biologic if the risk of psoriasis flare is high. }\end{array}$ \\
\hline COVID-19 infection & $\begin{array}{l}\text { Anti-TNFs may be associated with better prognosis in } \\
\text { event of COVID-19 compared with conventional systemic } \\
\text { agents. Data lacking for other biologic classes. }\end{array}$ & $\begin{array}{l}\text { Insufficient data to inform risk management, There is no } \\
\text { data to suggest that patients should discontinue biologic } \\
\text { therapy during the pandemic. }\end{array}$ \\
\hline $\begin{array}{l}\text { SARS-CoV-2 vaccine } \\
\text { response }\end{array}$ & $\begin{array}{l}\text { Reduced seroconversion following first dose of BioNTech/ } \\
\text { Pfizer and AstraZeneca vaccines in immunomodulator- } \\
\text { treated psoriasis patients (particularly methotrexate). Lack } \\
\text { of data for post-2nd dose seroconversion. }\end{array}$ & Continue biologic agent while awaiting vaccination. \\
\hline Cancer & $\begin{array}{l}\text { Observational studies do not demonstrate an increased } \\
\text { cancer risk with biologic therapies. Longer term studies } \\
\text { required to account for potential latency between drug } \\
\text { exposure and cancer development. }\end{array}$ & $\begin{array}{l}\text { Encourage patients to participate in national cancer } \\
\text { screening programmes. Consider risks and benefits of } \\
\text { treatment discontinuation on case-by-case basis with } \\
\text { multidisciplinary team input. }\end{array}$ \\
\hline \multicolumn{3}{|l|}{ Cardiovascular } \\
\hline Heart failure & $\begin{array}{l}\text { Anti-TNFs may increase the risk of heart failure, though } \\
\text { data is lacking in psoriasis patients. }\end{array}$ & $\begin{array}{l}\text { Anti-TNF agents are relatively contraindicated in heart } \\
\text { failure; other classes should be considered in this context. }\end{array}$ \\
\hline $\begin{array}{l}\text { Major cardiovascular } \\
\text { events (MACE) }\end{array}$ & Little data supporting biologics contributing to MACE. & $\begin{array}{l}\text { No evidence to influence biologic-selection in those at } \\
\text { high risk of MACE. }\end{array}$ \\
\hline Pregnancy & $\begin{array}{l}\text { Certolizumab pegol does not cross the placenta. Limited } \\
\text { data on anti-TNFs, ustekinumab and secukinumab suggests } \\
\text { no increases in prematurity, fetal death or teratogenicity } \\
\text { but studies have limitations. }\end{array}$ & $\begin{array}{l}\text { Certolizumab pegol could be considered a first-line option } \\
\text { in women planning conception. Neonates born to mothers } \\
\text { taking biologics beyond } 16 \text { weeks' gestation should avoid } \\
\text { live vaccines in the first } 6 \text { months. }\end{array}$ \\
\hline Breastfeeding & $\begin{array}{l}\text { Biologics are protein molecules and unlikely to be } \\
\text { absorbed systemically from breastmilk, though there is no } \\
\text { confirmatory data }\end{array}$ & $\begin{array}{l}\text { Inform women that breastfeeding should be safe } \\
\text { theoretically, but there is no evidence to confirm this. }\end{array}$ \\
\hline \multicolumn{3}{|l|}{ Other } \\
\hline Mental health & $\begin{array}{l}\text { Biologic initiation associated with an improvement in } \\
\text { psychiatric symptoms. }\end{array}$ & $\begin{array}{l}\text { Psychiatric comorbidity should not influence choice of } \\
\text { biologic. }\end{array}$ \\
\hline $\begin{array}{l}\text { Cutaneous adverse } \\
\text { events }\end{array}$ & $\begin{array}{l}\text { A range of potential adverse events reported including } \\
\text { paradoxical psoriasis and eczema. }\end{array}$ & Insufficient data to inform risk management, \\
\hline IBD exacerbations & $\begin{array}{l}\text { Anti-IL- I7s associated with new onset or exacerbation of } \\
\text { existing IBD. }\end{array}$ & Avoid anti-ILI7s in patients with comorbid IBD \\
\hline
\end{tabular}


Table 2 (Continued).

\begin{tabular}{|l|l|l|}
\hline Adverse Event Type & Summary & Risk Management Strategies \\
\hline $\begin{array}{l}\text { Interstitial lung } \\
\text { disease }\end{array}$ & $\begin{array}{l}\text { Limited reports of interstitial lung disease secondary to } \\
\text { anti-TNFs, ustekinumab, ixekizumab and secukinumab. }\end{array}$ & Insufficient data to inform risk management. \\
\hline
\end{tabular}

35.7-64.0) compared with non-biologic systemic agents (IR $14.2,95 \%$ CI 11.5-17.4). ${ }^{28}$

More recently, a large cohort study of 44,239 participants (median follow-up 12 months), undertaken using electronic healthcare records in France, compared the risk of serious infection in biologic-treated psoriasis patients with each other and with those receiving apremilast, a phosphodiesterase-4 inhibitor. ${ }^{29}$ This showed an increased risk with infliximab (weighted hazard ratio [wHR] 1.79, 95\% CI 1.49-2.16) and adalimumab (wHR $1.22,95 \%$ CI 1.07-1.38), reduced risk with ustekinumab (wHR 0.79, 95\% CI 0.67-0.94) and no increased risk with secukinumab, ixekizumab, brodalumab, guselkumab and apremilast versus etanercept. ${ }^{29}$ However, when participants with comorbid inflammatory diseases such as inflammatory bowel disease and psoriatic arthritis were excluded, there was no difference between the adalimumab cohort compared with etanercept, though the difference was still significant for infliximab. ${ }^{29}$ Two other cohort studies of participants with psoriasis and/or psoriatic arthritis found that ustekinumab had a lower risk of serious infection compared with other biologic classes. ${ }^{30,31}$ Li et al undertook a retrospective cohort study of participants receiving biologics for psoriasis, psoriatic arthritis or both, and included 11,560 treatment episodes, with dispensing of biologic medication defining the index date. ${ }^{30}$ After propensity score weighting and adjustment for baseline covariates, there was a lower risk of serious infection with ustekinumab compared with anti-TNF treatment (hazard ratio [HR] $0.59,95 \%$ CI $0.39-0.90$ ), and this remained significant in a subgroup analysis of psoriasisonly participants. However, this study had a short followup duration of 6 months. The cohort study by Jin et al was similar in design and involved 123,838 biologic-exposed psoriasis and/or psoriatic arthritis participants. ${ }^{31}$ Relative to ustekinumab, all other biologics had a significantly increased risk of serious infections, with ORs ranging from 1.39 (certolizumab) to 2.98 (infliximab). The median follow-up for biologic treatments ranged from 161 to 305 days. An important limitation of both studies is that they both relied on data originating from insurance claims in the US, which may not represent uninsured populations. Furthermore, due to the nature of the data, psoriasis severity could not be included as a confounder.

Overall, these studies indicate that ustekinumab has a lower risk of serious infections relative to other classes, and infliximab has a higher risk. Therefore, ustekinumab could be used preferentially in patients at high risk of infection, whereas infliximab could be avoided. There are insufficient data to comment on risk associated with antiIL-17 and anti-IL-23 agents. A systematic review and meta-analysis combining data from such observational studies may delineate any differences between biologic classes or individual drugs more clearly. It is unclear whether biologics increase the risk of serious infection relative to untreated populations as observational studies have utilised actively treated comparators. Such a study would be challenging to interpret as active treatment is likely to be closely associated with other factors, such as disease severity and comorbidity profiles. There are also little data on more specific real-world situations, such as combined treatment. One study demonstrated a crude incidence of serious infection in those taking combined methotrexate and adalimumab of 23.3 (95\% CI 12.9-42), compared with 9.6 (95\% CI 5.3-17.3) for methotrexate. ${ }^{32}$ However, with only 11 cases in each cohort, the confidence intervals are broad and overlap, as they did also for adjusted relative risk calculations. While further studies would help to define risks of combined treatment, this can be challenging to assess in observational studies due to the very large sample sizes needed, and bias arising from variation of participant cohort characteristics and timing of therapies.

\section{Fungal Infections}

IL-17 is important in the immune response to fungal infections. ${ }^{33}$ A systematic review of anti-IL17 trials found candida infection occurred in $1.7 \%, 4 \%$ and $3.3 \%$ of secukinumab, brodalumab and ixekizumab-treated participants, respectively, compared with $0.3 \%$ in the placebo group. ${ }^{34}$ Of the 395 total cases, one was classified as severe $(0.3 \%)$. Bimekizumab has subsequently been 
licensed, with phase III trial data showing between $6 \%$ and $19.3 \%$ of the participants in bimekizumab arms developing candidiasis, though the longest follow-up was 56 weeks. ${ }^{19,35-37}$ In the BE RADIANT phase III trial of bimekizumab versus secukinumab, 12.9-19.3\% of bimekizumab treated participants developed candidal infection compared with $3 \%$ in the secukinumab arm. ${ }^{37}$ These data indicate that bimekizumab may be more likely to cause candidal infections than other anti-IL17s. In patients where fungal infection is a concern, other biologic classes may be more suitable, real-world data over longer follow-up periods are required to define the risk of candida infection in the long term.

\section{Tuberculosis}

Due to potential risk of tuberculosis (TB) acquisition or reactivation, clinical practice guidelines frequently recommend screening with an interferon gamma release assay prior to biologic initiation. ${ }^{38-40}$ A meta-analysis of RCTs of anti-TNFs used for psoriatic arthritis, rheumatoid arthritis and ankylosing spondylitis demonstrated an increased odds of developing TB in participants receiving anti-TNFs (OR 1.94; 95\% CI 1.10-3.44) compared with controls. ${ }^{41}$ Subgroup analysis indicated the risk was greatest in those patients with rheumatoid arthritis. To our knowledge, no similar studies or observational studies of TB risk in psoriasis patients have been undertaken.

There are data from psoriasis IL-17 and IL-23 inhibitor trial extensions and safety analyses on latent tuberculosis infection rates among treated participants, as summarised by Nogueira et al. $^{42}$ These showed two cases of reactivation of latent tuberculosis in participants receiving ustekinumab, and none in those receiving secukinumab, ixekizumab, brodalumab, guselkumab, tildrakizumab and risankizumab, though anti-tuberculous therapy was used concomitantly in some of these trials. ${ }^{42}$ The IMMhance trial included risankizumab treatment for 31 participants with latent tuberculosis who did not receive anti-tuberculous therapy, and there were no cases of reactivation. ${ }^{43}$ In practice, patients are usually screened for tuberculosis with an interferon gamma release assay prior to initiation of biologic therapy and latent tuberculosis treated prior to commencement of biologic therapy. ${ }^{38}$ In patients with latent TB where urgent treatment of psoriasis is needed and cannot wait for anti-TB therapy, risankizumab has the strongest evidence base for safe use in this context, whereas anti-TNFs should be avoided.

\section{Post-Operative Infection}

While there are limited data on post-operative infection risk of anti-TNF treatment in psoriasis patients, several studies have been conducted in participants with inflammatory bowel disease (IBD). Some meta-analyses have concluded that anti-TNF agents are associated with an increased risk of post-operative infections in patients with IBD, ${ }^{44-47}$ whereas others have found no increase in risk. ${ }^{48-50}$ Conflicting data may be a result of heterogeneity of studies included in these meta-analyses and small sample sizes. ${ }^{51}$ In a small cohort study of 60 participants taking either anti-TNF agents or ustekinumab, there was no significant difference in the rate of post-operative wound infection. ${ }^{52}$ This study lacked a non-biologic control group. George et al undertook a retrospective cohort study in participants receiving infliximab for IBD, psoriasis or inflammatory arthritis and found no difference in infection risk after withholding treatment for $<4$ weeks compared with 8-12 weeks (OR 0.90, 95\% CI $0.60-1.34) .{ }^{53}$ There are no data available on post-operative infection risk for anti-IL17 or anti-IL23 biologics. Given the lack of data in psoriasis patients, some clinical practice guidelines recommend case-by-case consideration on whether to pause biologic treatment. ${ }^{38}$ The joint American Academy of Dermatology-National Psoriasis Foundation (AAD-NPF) guidelines recommend continuation of biologic therapy during low-risk surgical procedures, but case-by -case consideration for moderate- or high-risk procedures. ${ }^{40}$

\section{Coronavirus-19}

Given the increase in risk of infection with some biologics as described above, it is plausible that biologics could attenuate the immune-response to severe acute respiratory syndrome coronavirus-2 (SARS-CoV-2) and therefore increase the risk of severe COVID-19. Early in the pandemic, Gisondi et al conducted a retrospective observational study of 5206 psoriasis patients on biologic therapy and recorded clinical data from patient records or contact. $^{54}$ There were no COVID-19 related deaths, compared with an incidence rate of 1.6 in the general population, and fewer patients hospitalised. This study had no control group, however. Another study with 600 participants found that anti-TNF exposure reduced the odds of hospitalisation in participants with rheumatic disease, while corticosteroid exposure more than or equal to $10 \mathrm{mg}$ per day increased the odds of hospitalisation. ${ }^{55}$ Presumably due to sample size considerations, different biologic and non-biologic drugs were pooled together for 
analysis and so it is not possible to comment on drugspecific effects. A more recent cohort study by Izadi et al combined data from a number of registries spanning different countries and disease domains, and included 6077 participants receiving immunomodulators for immunemediated inflammatory diseases (IMIDs) including psoriasis. ${ }^{56}$ This found that compared with anti-TNF monotherapy, higher odds of hospitalization or death associated with COVID-19 were found in those receiving methotrexate monotherapy (OR 2.00, 95\% CI 1.57-2.56) and other oral therapy regimens. There was no significant difference between those on anti-TNF monotherapy versus anti-TNF combined with methotrexate (OR 1.18, 95\% CI 0.85-1.63). There are several important limitations of this study. There are regional differences in COVID-19 treatment practices and public health guidance, which could mean different incidence of COVID-19 across participant groups. Furthermore, non-anti-TNF biologic classes pertinent to psoriasis treatment were not included. A smaller study ( $\mathrm{n}=374$ ) utilising data from the PsoProtect registry, which is a global clinician-reported registry for cases of COVID-19 in people with psoriasis, did incorporate all biologic classes used for psoriasis. ${ }^{57}$ Compared with biologic therapies, non-biologic systemic therapies were associated with a higher risk of hospitalization due to COVID19 (OR 2.72, 95\% CI 1.37-5.40); there was no significant difference from a control group not receiving systemic treatment. The main limitations of this study are the small sample size, resulting in wide confidence intervals, and open to selection bias as the PsoProtect registry relies on clinicians to report cases. The available data suggests that biologics, particularly anti-TNFs, may be associated with better prognosis in the event of COVID-19 compared with oral systemic agents. Larger datasets are needed to delineate the influence of specific drugs and other biologics such as IL-17 and IL-23 inhibitors on COVID-19 outcome.

Vaccination is a key long-term strategy in controlling the pandemic, and the potential influence of biologics on immunity following vaccination is an important consideration. One study of 26 participants receiving one or more biologic or non-biologic immunomodulators for IMIDs found that average anti-SARS-CoV-2 IgG titres were lower in this group compared with 42 healthy controls, 7 days after the second dose of the BioNTech/Pfizer or Moderna vaccines. ${ }^{58}$ The sample size was small and immunomodulator drugs taken quite heterogeneous, including anti-TNFs, anti-IL17s, ustekinumab, tocilizumab
(anti-IL-6), vedolizumab (anti- $\alpha_{4} \beta_{7}$ integrin) and belimumab (anti-B-cell activating factor). Furthermore, statistical analysis was undertaken using the Mann-Whitney test without adjustment for confounding variables. Our group found that of 120 participants receiving biologics or oral immunomodulators for psoriasis or other IMID, $85 \%$ had detectable anti-SARS-CoV-2 immunoglobulin following the first dose of BioNTech/Pfizer and AstraZeneca vaccines. ${ }^{59}$ Furthermore, relative to biologics, there was a reduced odds of anti-spike IgG production with oral immunomodulators (OR $0.18,95 \%$ CI $0.06-0.59$ ) and reduced odds of total anti-spike immunoglobulin with combined biologic and oral immunomodulators (OR $0.06,95 \%$ CI $0.01-0.80) .{ }^{59}$ A strength of this study was that it identified those with prior infection (including asymptomatic infection) by measuring anti-nucleocapsid antibodies present following infection but not vaccination. Limitations included a heterogeneous study population with small numbers of participants on some biologics, and disease type was not included as a confounder in the logistic regression model. Mahil et al examined humoral and cellular responses to first-dose BioNTech/Pfizer vaccine in psoriasis patients on biologics or methotrexate $(\mathrm{n}=87)$ versus healthy controls $(\mathrm{n}=17)$ by measuring antispike protein IgG, antibody neutralising ability and IL-2 and IL-21 responses to SARS-CoV-2 spike glycoprotein peptides. ${ }^{60}$ The median treatment duration was 3.3 years. The results showed reduced seroconversion rates in immunomodulator-treated psoriasis participants $(78 \%, 95 \% \mathrm{CI}$ $67-87 \%)$ compared with healthy controls $(100 \%, 95 \%$ CI 80-100\%) after first-dose of the BioNTech/Pfizer vaccine. Importantly, this was lowest in those receiving methotrexate $(47 \%, 95 \%$ CI $21-73 \%)$. Seroconversion rates by biologic class were $79 \%$ for anti-TNF, $100 \%$ for anti-IL17 and $83 \%$ for anti-IL23 participants. Median spike-specific IgG titres were also lower in immunomodulator-treated participants relative to controls. There was no significant difference in IgG titres between methotrexate and biologic-treated psoriasis patients. Neutralising antibody activity and cellular responses were preserved in biologictreated patients relative to controls. ${ }^{60}$ In those receiving methotrexate, neutralising antibody activity was significantly lower than in controls, though cellular responses were maintained. While the data are quite convincing for the effect of methotrexate on seroconversion versus controls, a larger sample size is needed to conclude whether there is a significant difference between methotrexate and biologics, and between biologic classes. 
While the vaccine data presented have several limitations with regards to sample sizes, participant heterogeneity, relevance to all vaccine types and variety of assays/ outcome measures used, they indicate that vaccination does elicit the appropriate neutralising antibody and cellular responses to vaccines in most patients receiving biologics. This group of patients could continue their biologic while awaiting vaccination. Patients taking nonbiologic systemic agents such as methotrexate have a lower chance of seroconversion on treatment and may benefit from pausing or postponing therapy around the time of vaccination. However, the effects of pausing treatment need to be understood through trials such as the Vaccine Response On/Off Methotrexate Study, which is a multicentre randomised controlled trial examining the effects of temporarily suspending methotrexate for 2 weeks after booster vaccination. ${ }^{61}$

Given the lack of data, variety of vaccine types, dosing regimens and intervals, and the heterogeneity of outcome measures for vaccine response, more data are needed to establish whether biologics influence vaccine effectiveness.

\section{Cancer}

Because cancers can evade immune surveillance, it is important to understand whether biologics increase the risk of malignancy. Peleva et al undertook a systematic review of eight observational studies ( 7 on anti-TNFs, 1 on ustekinumab) and found no evidence of increased cancer risk on biologic therapies, though limitations of included studies were noted such as inadequate adjustment for confounders and follow-up period that may be too short. ${ }^{62}$ A nested case-control study, using multi-national registry data from Psonet (European Registry of Psoriasis), included 728 cases (patients who developed an incident cancer) and 2671 controls. ${ }^{63}$ This study found that the risk of first cancers was not significantly associated with biologic exposure, with an adjusted odds ratio (OR) per year of $1.02(95 \%$ CI $0.92-1.13){ }^{63}$

Recent studies have examined the risk of skin cancers in this population. Two cohort studies by Mason et al utilised BADBIR to examine the risk of keratinocyte skin cancers (basal cell carcinoma $[\mathrm{BCC}]$ and squamous cell carcinoma [SCC]) in participants that had no prior history of keratinocyte cancers, ${ }^{64}$ and in those with a prior history of keratinocyte cancer. ${ }^{65}$ The first study included 14,800 participants, with 9398 in the biologic cohort and 5402 in the non-biologic systemic cohort. ${ }^{64}$
Compared with non-biologic systemic therapy, there was no increased risk of BCC (adjusted HR [aHR] 1.20, 95\% CI $0.71-2.04$ ) or SCC (aHR 1.19, 95\% CI 0.59-2.40) in the biologic cohort. The second study included 267 participants with a prior history of BCC and/or SCC, and found no association between biologic therapy and development of BCC (aHR 0.89, 95\% CI 0.42-1.89) or SCC (aHR 0.83, 95\% CI $0.37-1.89) .{ }^{65}$ The main limitation of both studies was the low number of cases of BCC/SCC in both cohorts, which might mask smaller effect sizes of biologic therapies on keratinocyte cancer risk. Regarding melanoma risk, a systematic review of seven cohort studies identified no statistically significant increase in risk in biologictreated psoriasis patients (HR 1.57, 95\% CI 0.61-4.09); however, the authors concluded that more robust studies with larger patient numbers are needed. ${ }^{66}$

While the data so far are reassuring, many of the biologics used in psoriasis are relatively new and the potential latency between drug exposure and cancer development means that ongoing data collection within registries is needed to establish long-term risk of new or recurrent cancer with biologic therapy. Therefore, the authors' opinion is that the choice of biologic agent should not be influenced by potential cancer risk. To mitigate potential risk, clinical guidelines suggest encouraging patients to participate in national cancer screening programmes and to consider risks and benefits of treatment discontinuation on a case-by-case basis with multidisciplinary team and oncology input. ${ }^{38,40}$

\section{Cardiovascular Risks}

Due to the potential role of TNF- $\alpha$ in heart failure (HF) pathogenesis, ${ }^{67}$ infliximab was trialled on 150 patients with New York Heart Association class III or IV heart failure. ${ }^{68}$ Unfortunately, infliximab at a dose of $10 \mathrm{mg} / \mathrm{kg}$ was associated with an increase in all-cause death and hospitalisation due to HF. ${ }^{68}$ There have also been reports of HF developing or worsening in anti-TNF-treated patients, including in 19 people without risk factors for heart disease. ${ }^{69}$ To our knowledge, no studies have evaluated the risk of HF on anti-TNFs or other biologic classes in psoriasis patients. Registry and observational studies of anti-TNF-treated rheumatoid arthritis patients suggest that anti-TNFs do not increase the risk of HF. $^{70-73}$ However, these studies had limitations and varying methodology. Two used hospital admission or mortality from HF as an outcome measure, ${ }^{71,72}$ whereas others used healthcare records/participant recall of diagnosis or diagnostic tests for diastolic HF. ${ }^{70,73}$ Two studies had relatively small sample 
sizes, ${ }^{72,73}$ which limit the detection of smaller effect sizes, and one had retrospective design. ${ }^{72}$

Unlike with HF, the risk of major cardiovascular events (MACE), such as acute coronary syndromes and strokes, with biologic therapy has been studied in psoriasis patients. A cohort study included 5468 biologic-naïve who were subsequently exposed to ustekinumab $(\mathrm{n}=951)$, etanercept $(\mathrm{n}=1313)$, adalimumab $(\mathrm{n}=3204)$ and methotrexate $(n=2189)$ with a median follow-up of 2 years. ${ }^{74}$ There were no differences in risk of MACE between ustekinumab vs anti-TNF (aHR 0.96, 95\% CI 0.41-2.22), etanercept vs adalimumab (aHR 0.81, 95\% CI 0.28-2.30) and methotrexate vs adalimumab (aHR 1.05, 95\% CI 0.34-3.28). ${ }^{74}$ The wide CIs suggest that a larger sample size may be needed to more precisely estimate risk. Furthermore, similar to cancers, there may be a longer lag time before exposure and onset of adverse event which require longer follow-up periods to detect. A casetime-control study by Poizeau et al utilised the French national health insurance database to assess whether initiation of ustekinumab was associated with an increased incidence of MACE in psoriasis patients with either high or low cardiovascular risk. ${ }^{75}$ There were 9290 ustekinumab-exposed patients with psoriasis $(\mathrm{n}=7974)$ or Crohn disease $(n=1110)$, with high cardiovascular risk defined as possessing two risk factors or a personal history of atherothrombotic disease. Of the 98 participants with a MACE, those with a high cardiovascular risk were more likely to have started ustekinumab in the riskperiod ( 6 months prior to the adverse event) compared to the reference period (6-12 months prior to adverse event) [OR 4.17, 95\% CI 1.19-14.59]. There was no increase in risk during the risk period for those in the low cardiovascular risk cohort (OR $0.30,95 \%$ CI $0.03-3.13$ ). With this type of study design, it is difficult to control for confounders that are also time-dependent, such as psoriasis severity. For example, patients early in treatment might have more-poorly controlled disease, which increases the likelihood of the adverse event in question. Further potential limitations are summarised by de Brito et al and includes the arbitrary selection of 6 months as the risk-period cutoff and tendency of therapy adverse events to cluster early in susceptible individuals, leaving a relatively healthy cohort for analysis in the later time category. ${ }^{76}$

Pooled trial and post-marketing surveillance data reassuringly demonstrated a low risk of MACE in psoriasis patients receiving secukinumab ( 0.3 exposure adjusted incidence rates per 100 patient-years); however, data for control participants were not available. ${ }^{77}$ To our knowledge, no data examining the risk of MACE have been published for other anti-IL17s or the anti-IL23s.

In conclusion, while there is conflicting evidence linking anti-TNF agents to onset or exacerbation of heart failure, there is little data to support biologics contributing to MACE such as myocardial infarction or stroke. Therefore, in patients with heart failure, anti-TNF agents are relatively contraindicated and alternative classes may be more suitable. ${ }^{38,40}$ Anti-TNF treatment should be stopped in the event of new or worsening heart failure, and specialist advice sought. ${ }^{38}$ There is no strong evidence to suggest preferential selection of one biologic class over another in those at higher risk of MACE.

\section{Biologics in Pregnancy and Breastfeeding}

Potential risks of biologic therapy in pregnancy include teratogenicity, increased risk of spontaneous abortion and neonate immunomodulation. Most data for biologic use in pregnancy are for anti-TNF agents, as these have been used for the longest in psoriasis. While anti-TNF agents do cross the placenta (with the exception of certolizumab pegol), there is no evidence of teratogenicity or increased spontaneous abortion risk in animal models. ${ }^{78}$ A systematic review of IBD literature included 58 studies containing 1533 or more anti-TNF-exposed pregnant women identified no adverse outcomes in the mother or neonate. ${ }^{79}$ A subsequent systematic review of four cohort studies in psoriasis patients identified an increased odds of teratogenicity or preterm birth in anti-TNF treated patients in several studies, but this did not reach statistical significance in all of them. ${ }^{80}$ The quality of evidence of all four studies included in this review was classified as "very low" using an adapted GRADE toolkit due to various sources of bias, inconsistency and studies being carried out in indirect populations of women without known psoriasis.

Placental transfer of maternal IgG to the fetus is important for its immunological protection and is mediated by the FcRn receptor on syncytiotrophoblast (placental epithelial) cells that bind to the $\mathrm{Fc}$ fragment of $\mathrm{IgG}^{81}$ Certolizumab pegol is a pegylated anti-TNF IgG1 antibody that lacks the $\mathrm{Fc}$ antibody fragment, and therefore does not undergo FcRn-mediated transfer across the placenta. ${ }^{82}$ Analysis of prospectively collected data from 528 reported pregnancies known outcomes after maternal 
exposure to certolizumab pegol showed no increased risk of teratogenicity or fetal death compared with the general population. $^{83}$

Regarding other biologic classes, data are very limited. One retrospective cohort study of ustekinumab-treated IBD patients found no increase in prematurity, fetal death or teratogenicity when compared with anti-TNF-exposed patients. ${ }^{84}$ However, the sample size was small (29 cases and 76 controls). Another study of 292 patients with maternal exposure secukinumab used for psoriasis, psoriatic arthritis, ankylosing spondylitis and other indications found rates of fetal death and teratogenicity in line with the general population, though this study lacked a control group. ${ }^{85}$ In the absence of well-designed studies specifically addressing biologic exposure in psoriasis during pregnancy, no firm conclusions about safety in pregnancy can be reached. As is the case for other undefined risks, decisions regarding treatment need to be made on a caseby-case basis and clinical practice guidelines may differ. The joint ADD-NPF guidelines note that anti-TNF treatment is safe during pregnancy and lactation, but the risk for other classes is unknown. ${ }^{40}$ The BAD guidelines recommend that women of childbearing potential use effective contraception while on biologic therapy and that certolizumab pegol could be considered a first-line option when starting biologic therapy in women planning conception. ${ }^{38}$ Furthermore, due to the potential presence of biologic drug in neonates born to mothers taking biologics beyond 16 weeks' gestation, live vaccines should be avoided in the first 6 months in these infants. ${ }^{38}$

In the case of breastfeeding, biologics are protein molecules and are unlikely to be absorbed systemically, ${ }^{38}$ and breastfed infants of biologic-treated mothers appear to suffer no more complications relative to non-breastfed infants or infants unexposed to these drugs. ${ }^{86}$

Our perspective is that certolizumab pegol should be considered in women planning conception, continuation of other treatments during pregnancy should be decided on a case-bycase basis. Women wanting to breast-feed while on biologic therapy should be informed that this should be safe theoretically, but that there is no evidence to confirm this yet.

\section{Other Risks}

\section{Mental Health}

There is a known association between depression and psoriasis, and that biologic use is associated with a reduction in depressive symptoms. ${ }^{87,88}$ While there is no clear biologic mechanism through which the reverse could happen, ie, biologics inducing or exacerbating psychiatric symptoms, there were reports of psychiatric adverse events during Phase 3 trials of brodalumab. ${ }^{18}$ An analysis of brodalumab Phase 2 and 3 clinical trial data explored the possibility of brodalumab causing psychiatric adverse events. $^{89}$ The analysis included 4464 brodalumabexposed participants, with 564 receiving brodalumab after ustekinumab exposure. A higher proportion of the brodalumab cohort had improvement in anxiety and depression scores compared with placebo. At baseline, the proportion of patients with prior psychiatric disorders was similar among treatment arms (17.1\% placebo; 19.7\% ustekinumab; $17.5 \%$ brodalumab). There were 3 confirmed suicides in the brodalumab group. Rates of psychiatric adverse events were comparable among treatment groups, and the follow-up time-adjusted incidence rates of suicidal ideation and behaviour was comparable between the brodalumab and ustekinumab groups (0.20 vs 0.60 per 100 patient-years, respectively). A time-to-event analysis also revealed no temporal relationship between these events and brodalumab initiation. Limitations of this study result from inherent limitations in trials, which are not powered to study rare adverse events and do not typically include comparator arms after week 52 .

Current evidence indicates that biologic initiation is associated with an improvement, rather than worsening, of psychiatric symptoms. Therefore, psychiatric comorbidity should not be a barrier to biologic therapy or influence choice of biologic.

\section{Inflammatory Adverse Events}

A range of paradoxical inflammatory reactions to biologics have been reported, including cutaneous adverse events, IBD and interstitial lung disease. Reported skin reactions to biologics in patients with rheumatological disorders, IBD and psoriasis include paradoxical psoriasis, eczema, pustular disorders and lichenoid eruptions. ${ }^{90}$ In the case of eczema developing in biologic-treated psoriasis patients, a systematic review of published cases, observational studies and trial data found that in those with reported treatment outcomes, $46 \%$ of the patients discontinued their biologic treatment and there was significant heterogeneity in treatment strategies. ${ }^{91}$ While this figure could be skewed by publication bias, it highlights the potential impact of cutaneous adverse events on affected patients. Factors predisposing patients to eczematous reactions are unclear, but included a prior history of atopy in $46 \%$ of 
published cases. ${ }^{91}$ There have been no observational studies in psoriasis patients to confirm an association with clinical or demographic factors, though an integrated safety analysis of ixekizumab trial data found an association between prior history of eczema and development of eczema on ixekizumab, ustekinumab or etanercept. ${ }^{92}$

At this stage, it is not possible to anticipate which patients will develop cutaneous adverse events in order to manage risk or guide therapy selection. A range of research methodologies are needed to understand the molecular and immunological basis of these events, genetic risk and clinical risk factors for cutaneous adverse events in order to achieve this aim and reduce risk for patients.

While IBD can be treated with anti-TNF agents and ustekinumab, anti-IL-17s can paradoxically flare IBD. This was first noted in clinical trials of anti-IL17s in patients with IBD. ${ }^{93,94}$ Subsequent trials of anti-IL17s for patients with psoriasis, psoriatic arthritis, rheumatoid arthritis and ankylosing spondylitis also resulted in new cases of IBD secondary to secukinumab, ixekizumab and brodalumab. ${ }^{95,96}$ There have been no reported cases of new or exacerbated of IBD secondary to bimekizumab to date. As summarised by Fauny et al, there are also case reports of IBD developing in psoriasis patients treated with anti-IL17s. ${ }^{97}$ A recent cohort study of the French national healthcare system database compared the risk of new-onset IBD in 16,793 anti-IL17 users with 20,556 apremilast users and 10,245 etanercept users. ${ }^{98}$ After adjusting for disease severity, there was no greater risk of IBD in anti-IL17 users compared with those on etanercept, though the risk was greater than users of apremilast. This is the first such study to date, and further similar studies need to be conducted. Based on current evidence, use of anti-IL17s in patients with IBD should be avoided. Patients developing symptoms of IBD while on anti-IL17s should be investigated and consideration given to withdrawing treatment.

Interstitial lung disease has also recently been reported as a potential adverse event to all biologic classes used in psoriasis. $^{99,100}$ One retrospective review of 603 psoriasis patients on anti-IL17/23 biologics identified six cases of interstitial lung disease occurring at a mean of 14 months after biologic initiation, with five improving after drug cessation. ${ }^{98}$ Another series identified eight cases on antiTNF agents, and one case each on secukinumab, ixekizumab and ustekinumab. ${ }^{100}$ A retrospective cohort study published in 2015 found no difference in risk of interstitial lung disease in rheumatoid arthritis patients treated with
anti-TNFs versus those receiving abatacept, rituximab or tocilizumab. ${ }^{101}$ Given the lack of data, it is not possible to conclude whether biologics used in patients with psoriasis are truly associated with an increased risk of interstitial lung disease.

\section{Conclusions}

While it is not possible to cover all potential treatment risks and management strategies, this review summarises the evidence base for key risks of interests. The uncertainty surrounding risk of some of these risks outlined above highlights the importance of well-designed, properly controlled observational studies and registries that collect data prospectively over long periods of time. Risk management starts from initial consultation with the patient for example, by establishing comorbidities that may preclude use of certain biologic treatments. Balance of risks versus benefits is inherent in clinical practice, and needs to be applied when considering biologic therapy, particularly where the available body of evidence is not robust. As well as further research identifying and quantifying risk in the psoriasis cohort as a whole, it is important to understand which factors drive differential treatment response and adverse event onset in order to improve personalisation of therapy.

\section{Funding}

No funding was required to support this work.

\section{Disclosure}

The authors report no conflicts of interest in this work.

\section{References}

1. Parisi R, Iskandar IYK, Kontopantelis E, Augustin M, Griffiths CEM, Ashcroft DM. National, regional, and worldwide epidemiology of psoriasis: systematic analysis and modelling study. BMJ. 2020;369: m1590. doi:10.1136/bmj.m1590

2. Szepietowski JC, Reich A. Pruritus in psoriasis: an update. Eur J Pain. 2016;20(1):41-46. doi:10.1002/ejp.768

3. Amatya B, Wennersten G, Nordlind K. Patients' perspective of pruritus in chronic plaque psoriasis: a questionnaire-based study. $J$ Eur Acad Dermatol Venereol. 2008;22(7):822-826. doi:10.1111/j.14683083.2008.02591.x

4. Miller IM, Ellervik C, Yazdanyar S, Jemec GB. Meta-analysis of psoriasis, cardiovascular disease, and associated risk factors. $\mathrm{J} \mathrm{Am} \mathrm{Acad} \mathrm{Dermatol.}$ 2013;69(6):1014-1024. doi:10.1016/j.jaad.2013.06.053

5. Duan X, Liu J, Mu Y, et al. A systematic review and meta-analysis of the association between psoriasis and hypertension with adjustment for covariates. Medicine (Baltimore). 2020;99(9):e19303. doi:10.1097/ MD.0000000000019303

6. Armstrong AW, Harskamp CT, Armstrong EJ. Psoriasis and the risk of diabetes mellitus: a systematic review and meta-analysis. JAMA Dermatol. 2013;149(1):84-91. doi:10.1001/2013.jamadermatol.406 
7. Singh S, Young P, Armstrong AW. Relationship between psoriasis and metabolic syndrome: a systematic review. G Ital Dermatol Venereol. 2016;151(6):663-677.

8. Kryczek I, Bruce AT, Gudjonsson JE, et al. Induction of IL-17+ $\mathrm{T}$ cell trafficking and development by IFN- $\gamma$ : mechanism and pathological relevance in psoriasis. $J$ Immunol. 2008;181 (7):4733-4741. doi:10.4049/jimmunol.181.7.4733

9. Austin LM, Ozawa M, Kikuchi T, Walters IB, Krueger JG. The majority of epidermal $\mathrm{T}$ cells in psoriasis vulgaris lesions can produce type 1 cytokines, interferon- $\gamma$, interleukin-2, and tumor necrosis factor- $\alpha$, defining TC1 (cytotoxic T lymphocyte) and TH1 effector populations: a type 1 differentiation bias is also measured in circulating blood $\mathrm{T}$ cells in psoriatic patients. J Invest Dermatol. 1999;113(5):752-759. doi:10.1046/j.15231747.1999.00749.x

10. Ortega C, Fernández AS, Carrillo JM, et al. IL-17-producing CD8 $+\mathrm{T}$ lymphocytes from psoriasis skin plaques are cytotoxic effector cells that secrete Th17-related cytokines. J Leukoc Biol. 2009;86(2):435-443. doi:10.1189/JLB.0109046

11. Zaba LC, Fuentes-Duculan J, Eungdamrong NJ, et al. Psoriasis is characterized by accumulation of immunostimulatory and Th1/ Th17 cell-polarizing myeloid dendritic cells. $J$ Invest Dermatol. 2009;129(1):79-88. doi:10.1038/jid.2008.194

12. Menter A, Tyring SK, Gordon K, et al. Adalimumab therapy for moderate to severe psoriasis: a randomized, controlled phase III trial. J Am Acad Dermatol. 2008;58(1):106-115. doi:10.1016/j. jaad.2007.09.010

13. Gottlieb AB, Blauvelt A, Thaçi D, et al. Certolizumab pegol for the treatment of chronic plaque psoriasis: results through 48 weeks from 2 phase 3, multicenter, randomized, double-blinded, placebo-controlled studies (CIMPASI-1 and CIMPASI-2). $J \mathrm{Am}$ Acad Dermatol. 2018;79(2):302-314.e306. doi:10.1016/j. jaad.2018.04.012

14. Leonardi CL, Powers JL, Matheson RT, et al. Etanercept as monotherapy in patients with psoriasis. $N$ Engl J Med. 2003;349 (21):2014-2022. doi:10.1056/NEJMoa030409

15. Reich K, Nestle FO, Papp K, et al. Infliximab induction and maintenance therapy for moderate-to-severe psoriasis: a phase III, multicentre, double-blind trial. Lancet. 2005;366 (9494):1367-1374. doi:10.1016/S0140-6736(05)67566-6

16. Langley RG, Elewski BE, Lebwohl M, et al. Secukinumab in plaque psoriasis - results of two phase 3 trials. $N$ Engl $J$ Med. 2014;371(4):326-338. doi:10.1056/NEJMoa1314258

17. Gordon KB, Blauvelt A, Papp KA, et al. Phase 3 trials of ixekizumab in moderate-to-severe plaque psoriasis. $N$ Engl $J$ Med. 2016;375(4):345-356. doi:10.1056/NEJMoa1512711

18. Lebwohl M, Strober B, Menter A, et al. Phase 3 studies comparing brodalumab with ustekinumab in psoriasis. $N$ Engl $J$ Med. 2015;373(14):1318-1328. doi:10.1056/NEJMoa1503824

19. Gordon KB, Foley P, Krueger JG, et al. Bimekizumab efficacy and safety in moderate to severe plaque psoriasis (BE READY): a multicentre, double-blind, placebo-controlled, randomised withdrawal phase 3 trial. Lancet. 2021;397(10273):475-486. doi:10.1016/S0140-6736(21)00126-4

20. Papp KA, Langley RG, Lebwohl M, et al. Efficacy and safety of ustekinumab, a human interleukin-12/23 monoclonal antibody, in patients with psoriasis: 52-week results from a randomised, double-blind, placebo-controlled trial (Phoenix 2).. Lancet. 2008;371(9625):1675-1684. doi:10.1016/S0140-6736(08)60726-6

21. Reich K, Armstrong AW, Foley P, et al. Efficacy and safety of guselkumab, an anti-interleukin-23 monoclonal antibody, compared with Adalimumab for the treatment of patients with moderate to severe psoriasis with randomized withdrawal and retreatment: results from the phase III, double-blind, placeboand active comparator-controlled VOYAGE 2 trial. $\mathrm{J} \mathrm{Am} \mathrm{Acad}$ Dermatol. 2017;76(3):418-431. doi:10.1016/j.jaad.2016.11.042
22. Gordon KB, Strober B, Lebwohl M, et al. Efficacy and safety of risankizumab in moderate-to-severe plaque psoriasis (UltIMMa-1 and UltIMMa-2): results from two double-blind, randomised, placebo-controlled and ustekinumab-controlled phase 3 trials. Lancet. 2018;392(10148):650-661. doi:10.1016/S0140-6736(18) 31713-6

23. Reich K, Papp KA, Blauvelt A, et al. Tildrakizumab versus placebo or etanercept for chronic plaque psoriasis (reSURFACE 1 and reSURFACE 2): results from two randomised controlled, phase 3 trials. Lancet. 2017;390(10091):276-288. doi:10.1016/ S0140-6736(17)31279-5

24. Mason KJ, Barker JN, Smith $\mathrm{CH}$, et al. Comparison of drug discontinuation, effectiveness, and safety between clinical trial eligible and ineligible patients in BADBIR. JAMA Dermatol. 2018;154(5):581. doi:10.1001/jamadermatol.2018.0183

25. Warren RB, Smith CH, Yiu ZZN, et al. Differential drug survival of biologic therapies for the treatment of psoriasis: a prospective observational cohort study from the British Association of Dermatologists Biologic Interventions Register (BADBIR). $J$ Invest Dermatol. 2015;135(11):2632-2640. doi:10.1038/ jid.2015.208

26. Manounah L, Yiu ZZN, Mahil SK, et al. Risk of serious infections in patients with psoriasis on biologic therapies: an updated systematic review and meta-analysis. medRxiv. 2021. doi:10.1101/2021.08.27.21262722

27. Yiu ZZN, Smith CH, Ashcroft DM, et al. Risk of serious infection in patients with psoriasis receiving biologic therapies: a prospective cohort study from the British Association of Dermatologists Biologic Interventions Register (BADBIR). $J$ Invest Dermatol. 2018;138(3):534-541. doi:10.1016/j. jid.2017.10.005

28. Yiu ZZN, Ashcroft DM, Evans I, et al. Infliximab is associated with an increased risk of serious infection in patients with psoriasis in the U.K. and Republic of Ireland: results from the British Association of Dermatologists Biologic Interventions Register (BADBIR). Br J Dermatol. 2018;180(2):329-337. doi:10.1111/ bjd.17036

29. Penso L, Dray-Spira R, Weill A, Pina Vegas L, Zureik M, Sbidian E. Association between biologics use and risk of serious infection in patients with psoriasis. JAMA Dermatol. 2021;157 (9):1056. doi:10.1001/jamadermatol.2021.2599

30. Li X, Andersen KM, Chang H-Y, Curtis JR, Alexander GC. Comparative risk of serious infections among real-world users of biologics for psoriasis or psoriatic arthritis. Ann Rheum Dis. 2020;79(2):285-291. doi:10.1136/annrheumdis-2019-216102

31. Jin $Y$, Lee $H$, Lee MP, et al. Risk of hospitalized serious infection after initiating ustekinumab or other biologics for psoriasis or psoriatic arthritis. Arthritis Care Res. 2021. doi:10.1002/ acr. 24630

32. Dávila-Seijo P, Dauden E, Descalzo MA, et al. Infections in moderate to severe psoriasis patients treated with biological drugs compared to classic systemic drugs: findings from the BIOBADADERM registry. $J$ Invest Dermatol. 2017;137 (2):313-321. doi:10.1016/j.jid.2016.08.034

33. Ling Y, Puel A. IL-17 and infections. Actas Dermo Sifiliográficas. 2014;105:34-40. doi:10.1016/S0001-7310(14)70016-X

34. Saunte DM, Mrowietz U, Puig L, Zachariae C. Candida infections in patients with psoriasis and psoriatic arthritis treated with interleukin-17 inhibitors and their practical management. $\mathrm{Br}$ J Dermatol. 2017;177(1):47-62. doi:10.1111/bjd.15015

35. Reich K, Papp KA, Blauvelt A, et al. Bimekizumab versus ustekinumab for the treatment of moderate to severe plaque psoriasis (BE VIVID): efficacy and safety from a 52-week, multicentre, double-blind, active comparator and placebo controlled phase 3 trial. Lancet. 2021;397(10273):487-498. doi:10.1016/ S0140-6736(21)00125-2 
36. Warren RB, Blauvelt A, Bagel J, et al. Bimekizumab versus adalimumab in plaque psoriasis. $N$ Engl $J$ Med. 2021;385 (2):130-141. doi:10.1056/NEJMoa2102388

37. Reich K, Warren RB, Lebwohl M, et al. Bimekizumab versus secukinumab in plaque psoriasis. $N$ Engl J Med. 2021;385 (2):142-152. doi:10.1056/NEJMoa2102383

38. Smith $\mathrm{CH}$, Yiu ZZN, Bale T, et al. British Association of Dermatologists guidelines for biologic therapy for psoriasis 2020: a rapid update. Br J Dermatol. 2020;183(4):628-637. doi:10.1111/bjd.19039

39. Cantini F, Nannini C, Niccoli L, et al. Guidance for the management of patients with latent tuberculosis infection requiring biologic therapy in rheumatology and dermatology clinical practice. Autoimmun Rev. 2015;14(6):503-509. doi:10.1016/j. autrev.2015.01.011

40. Menter A, Strober BE, Kaplan DH, et al. Joint AAD-NPF guidelines of care for the management and treatment of psoriasis with biologics. J Am Acad Dermatol. 2019;80(4):1029-1072. doi:10.1016/j.jaad.2018.11.057

41. Zhang Z, Fan W, Yang G, et al. Risk of tuberculosis in patients treated with TNF- $\alpha$ antagonists: a systematic review and metaanalysis of randomised controlled trials. BMJ Open. 2017;7(3): e012567. doi:10.1136/bmjopen-2016-012567

42. Nogueira M, Warren RB, Torres T. Risk of tuberculosis reactivation with interleukin (IL)-17 and IL-23 inhibitors in psoriasis time for a paradigm change. J Eur Acad Dermatol Venereol. 2020;35(4):824-834. doi:10.1111/jdv.16866

43. Blauvelt A, Leonardi CL, Gooderham M, et al. Efficacy and safety of continuous risankizumab therapy vs treatment withdrawal in patients with moderate to severe plaque psoriasis. JAMA Dermatol. 2020;156(6):649. doi:10.1001/jamadermatol.2020.0723

44. Billioud V, Ford AC, Tedesco ED, Colombel J-F, Roblin X, Peyrin-Biroulet L. Preoperative use of anti-TNF therapy and postoperative complications in inflammatory bowel diseases: a meta-analysis. J Crohns Colitis. 2013;7(11):853-867. doi:10.1016/j.crohns.2013.01.014

45. Ali UA, Martin ST, Rao AD, Kiran RP. Impact of preoperative immunosuppressive agents on postoperative outcomes in Crohn's disease. Dis Colon Rectum. 2014;57(5):663-674. doi:10.1097/ DCR.0000000000000099

46. Narula N, Charleton D, Marshall JK. Meta-analysis: perioperative anti-TNF $\alpha$ treatment and post-operative complications in patients with inflammatory bowel disease. Aliment Pharmacol Ther. 2013;37(11):1057-1064. doi:10.1111/apt.12313

47. Yang Z-P, Hong L, Wu Q, Wu K-C, Fan D-M. Preoperative infliximab use and postoperative complications in Crohn's disease: a systematic review and meta-analysis. Int J Surg. 2014;12 (3):224-230. doi:10.1016/j.ijsu.2013.12.015

48. Xu Y, Yang L, An P, Zhou B, Liu G. Meta-analysis: the influence of preoperative infliximab use on postoperative complications of Crohn's disease. Inflamm Bowel Dis. 2019;25(2):261-269. doi:10.1093/ibd/izy246

49. Yang Z, Wu Q, Wang F, Wu K, Fan D. Meta-analysis: effect of preoperative infliximab use on early postoperative complications in patients with ulcerative colitis undergoing abdominal surgery. Aliment Pharmacol Ther. 2012;36(10):922-928. doi:10.1111/ apt. 12060

50. Rosenfeld G, Qian H, Bressler B. The risks of post-operative complications following pre-operative infliximab therapy for Crohn's disease in patients undergoing abdominal surgery: a systematic review and meta-analysis. J Crohns Colitis. 2013;7 (11):868-877. doi:10.1016/j.crohns.2013.01.019

51. Moosvi Z, Abadir A, Duong J, Nguyen D. Is it safe to continue biologic agents during surgery in patients with inflammatory bowel disease? Cleve Clin J Med. 2020;87(6):343-346. doi:10.3949/ccjm.87a.19071
52. Shim HH, Ma C, Kotze PG, et al. Preoperative ustekinumab treatment is not associated with increased postoperative complications in Crohn's disease: a Canadian multi-centre observational cohort study. J Can Assoc Gastroenterol. 2018;1(3):115-123. doi:10.1093/jcag/gwy013

53. George MD, Baker JF, Hsu JY, et al. Perioperative timing of infliximab and the risk of serious infection after elective hip and knee arthroplasty. Arthritis Care Res. 2017;69(12):1845-1854. doi:10.1002/acr.23209

54. Gisondi P, Facheris P, Dapavo P, et al. The impact of the COVID19 pandemic on patients with chronic plaque psoriasis being treated with biological therapy: the Northern Italy experience. Br J Dermatol. 2020;183(2):373-374. doi:10.1111/bjd.19158

55. Gianfrancesco M, Hyrich KL, Al-Adely S, et al. Characteristics associated with hospitalisation for COVID-19 in people with rheumatic disease: data from the COVID-19 global rheumatology alliance physician-reported registry. Ann Rheum Dis. 2020;79 (7):859-866. doi:10.1136/annrheumdis-2020-217871

56. Izadi Z, Brenner EJ, Mahil SK, et al. Association between tumor necrosis factor inhibitors and the risk of hospitalization or death among patients with immune-mediated inflammatory disease and COVID-19. JAMA Netw Open. 2021;4(10):e2129639. doi:10.1001/jamanetworkopen.2021.29639

57. Mahil SK, Dand N, Mason KJ, et al. Factors associated with adverse COVID-19 outcomes in patients with psoriasis - insights from a global registry-based study. J Allergy Clin Immunol. 2021;147(1):60-71. doi:10.1016/j.jaci.2020.10.007

58. Geisen UM, Berner DK, Tran F, et al. Immunogenicity and safety of anti-SARS-CoV-2 mRNA vaccines in patients with chronic inflammatory conditions and immunosuppressive therapy in a monocentric cohort. Ann Rheum Dis. 2021;80:1306-1311. doi:10.1136/annrheumdis-2021-220272

59. Al-Janabi A, Littlewood Z, Griffiths CEM, et al. Antibody responses to single-dose SARS-CoV-2 vaccination in patients receiving immunomodulators for immune-mediated inflammatory disease. $\mathrm{Br} J$ Dermatol. 2021;185(3):646-648. doi:10.1111/ bjd.20479

60. Mahil SK, Bechman K, Raharja A, et al. The effect of methotrexate and targeted immunosuppression on humoral and cellular immune responses to the COVID-19 vaccine BNT162b2: a cohort study. Lancet Rheumatol. 2021;3(9):e627-e637. doi:10.1016/ S2665-9913(21)00212-5

61. VROOM. VROOM home page; 2021. Available from: Vroom. octru.ox.ac.uk. Accessed November 1, 2021.

62. Peleva E, Exton LS, Kelley K, Kleyn CE, Mason KJ, Smith CH. Risk of cancer in patients with psoriasis on biological therapies: a systematic review. $\mathrm{Br} J$ Dermatol. 2017;178(1):103-113. doi: $10.1111 /$ bjd. 15830

63. Garcia-Doval I, Descalzo MA, Mason KJ, et al. Cumulative exposure to biological therapy and risk of cancer in patients with psoriasis: a meta-analysis of Psonet studies from Israel, Italy, Spain, the U.K. and Republic of Ireland. Br J Dermatol. 2018;179(4):863-871. doi:10.1111/bjd.16715

64. Mason KJ, Burden AD, Barker JN, et al. Risks of basal cell and squamous cell carcinoma in psoriasis patients after treatment with biologic vs non-biologic systemic therapies. J Eur Acad Dermatol Venereol. 2021;35(8):e496-e498. doi:10.1111/jdv.17282

65. Mason KJ, Burden AD, Barker JN, et al. Characteristics and skin cancer risk of psoriasis patients with a history of skin cancer in BADBIR. J Eur Acad Dermatol Venereol. 2021;35(8):e498-e501. doi:10.1111/jdv.17230

66. Esse S, Mason KJ, Green AC, Warren RB. Melanoma risk in patients treated with biologic therapy for common inflammatory diseases. JAMA Dermatol. 2020;156(7):787-794. doi:10.1001/ jamadermatol.2020.1300 
67. Azzawi M. Tumour necrosis factor alpha and the cardiovascular system: its role in cardiac allograft rejection and heart disease. Cardiovasc Res. 1999;43(4):850-859. doi:10.1016/S00086363(99)00138-8

68. Chung ES, Packer M, Lo KH, Fasanmade AA, Willerson JT. Randomized, double-blind, placebo-controlled, pilot trial of infliximab, a chimeric monoclonal antibody to tumor necrosis factor- $\alpha$, in patients with moderate-to-severe heart failure. Circulation. 2003;107(25):3133-3140. doi:10.1161/01. CIR.0000077913.60364.D2

69. Kwon HJ, Cot TR, Cuffe MS, Kramer JM, Braun MM. Case reports of heart failure after therapy with a tumor necrosis factor antagonist. Ann Intern Med. 2003;138(10):807-811. doi:10.7326/ 0003-4819-138-10-200305200-00008

70. Wolfe F, Michaud K. Heart failure in rheumatoid arthritis: rates, predictors, and the effect of anti-tumor necrosis factor therapy. Am J Med. 2004;116(5):305-311. doi:10.1016/j.amjmed.20 03.09.039

71. Solomon DH, Rassen JA, Kuriya B, et al. Heart failure risk among patients with rheumatoid arthritis starting a TNF antagonist. Ann Rheum Dis. 2013;72(11):1813-1818. doi:10.1136/annrheumdis-2012-202136

72. Cole J, Busti A, Kazi S. The incidence of new onset congestive heart failure and heart failure exacerbation in Veteran's Affairs patients receiving tumor necrosis factor alpha antagonists. Rheumatol Int. 2006;27(4):369-373. doi:10.1007/s00296-0060215-3

73. Schau T, Gottwald M, Arbach O, et al. Increased prevalence of diastolic heart failure in patients with rheumatoid arthritis correlates with active disease, but not with treatment type. $J$ Rheumatol. 2015;42(11):2029-2037. doi:10.3899/jrheum.1 41647

74. Rungapiromnan W, Mason KJ, Lunt M, et al. Risk of major cardiovascular events in patients with psoriasis receiving biologic therapies: a prospective cohort study. J Eur Acad Dermatol Venereol. 2020;34(4):769-778. doi:10.1111/jdv.16018

75. Poizeau F, Nowak E, Kerbrat S, et al. Association between early severe cardiovascular events and the initiation of treatment with the anti-interleukin 12/23p40 antibody ustekinumab. JAMA Dermatol. 2020;156(11):1208. doi:10.1001/jamadermatol.20 20.2977

76. de Brito M, Yiu ZZN. Cardiovascular safety of biologics targeting interleukin (IL)-12 and/or IL-23: what does the evidence say? Am $J$ Clin Dermatol. 2021;22(5):587-601. doi:10.1007/s40257-02100612-9

77. Deodhar A, Mease PJ, McInnes IB, et al. Long-term safety of secukinumab in patients with moderate-to-severe plaque psoriasis, psoriatic arthritis, and ankylosing spondylitis: integrated pooled clinical trial and post-marketing surveillance data. Arthritis Res Ther. 2019;21(1):111. doi:10.1186/s13075-019-1882-2

78. Yiu ZZN, Griffiths CEM, Warren RB. Safety of biological therapies for psoriasis: effects on reproductive potential and outcomes in male and female patients. $B r \quad J$ Dermatol. 2014;171 (3):485-491. doi:10.1111/bjd.13060

79. Nielsen $\mathrm{OH}$, Loftus Jr EV, Jess T. Safety of TNF- $\alpha$ inhibitors during IBD pregnancy: a systematic review. BMC Med. 2013;11 (1). doi:10.1186/1741-7015-11-174

80. Pottinger E, Woolf RT, Exton LS, Burden AD, Nelson-Piercy C, Smith $\mathrm{CH}$. Exposure to biological therapies during conception and pregnancy: a systematic review. $B r J$ Dermatol. 2017;178 (1):95-102. doi:10.1111/bjd.15802

81. Palmeira P, Quinello C, Silveira-Lessa AL, Zago CA, CarneiroSampaio M. IgG placental transfer in healthy and pathological pregnancies. Clin Dev Immunol. 2012;2012:1-13. doi:10.1155/ 2012/985646
82. Mariette X, Förger F, Abraham B, et al. Lack of placental transfer of certolizumab pegol during pregnancy: results from CRIB, a prospective, postmarketing, pharmacokinetic study. Ann Rheum Dis. 2018;77(2):228-233. doi:10.1136/annrheumdis2017-212196

83. Clowse MEB, Scheuerle AE, Chambers C, et al. Pregnancy outcomes after exposure to certolizumab pegol. Arthritis Rheumatol. 2018;70(9):1399-1407. doi:10.1002/art.40508

84. Wils P, Seksik P, Stefanescu C, et al. Safety of ustekinumab or vedolizumab in pregnant inflammatory bowel disease patients: a multicentre cohort study. Aliment Pharmacol Ther. 2021;53 (4):460-470. doi:10.1111/apt.16192

85. Warren RB, Reich K, Langley RG, et al. Secukinumab in pregnancy: outcomes in psoriasis, psoriatic arthritis and ankylosing spondylitis from the global safety database. $\mathrm{Br} J$ Dermatol. 2018;179(5):1205-1207. doi:10.1111/bjd.16901

86. Matro R, Martin CF, Wolf D, Shah SA, Mahadevan U. Exposure concentrations of infants breastfed by women receiving biologic therapies for inflammatory bowel diseases and effects of breastfeeding on infections and development. Gastroenterology. 2018;155(3):696-704. doi:10.1053/j.gastro.2018.05.040

87. Fleming P, Roubille C, Richer V, et al. Effect of biologics on depressive symptoms in patients with psoriasis: a systematic review. J Eur Acad Dermatol Venereol. 2015;29(6):1063-1070. doi:10.1111/jdv.12909

88. Strober B, Gooderham M, de Jong EM, et al. Depressive symptoms, depression, and the effect of biologic therapy among patients in Psoriasis Longitudinal Assessment and Registry (PSOLAR). $J$ Am Acad Dermatol. 2018;78(1):70-80. doi:10.1016/j.jaad.2017.08.051

89. Lebwohl MG, Papp KA, Marangell LB, et al. Psychiatric adverse events during treatment with brodalumab: analysis of psoriasis clinical trials. J Am Acad Dermatol. 2018;78(1):81-89.e85. doi:10.1016/j.jaad.2017.08.024

90. Garcovich S, De Simone C, Genovese G, Berti E, Cugno M, Marzano AV. Paradoxical skin reactions to biologics in patients with rheumatologic disorders. Front Pharmacol. 2019;10:282. doi:10.3389/fphar.2019.00282

91. Al-Janabi A, Foulkes AC, Mason K, Smith CH, Griffiths CEM, Warren RB. Phenotypic switch to eczema in patients receiving biologics for plaque psoriasis: a systematic review. J Eur Acad Dermatol Venereol. 2020;34(7):1440-1448. doi:10.1111/ jdv. 16246

92. Brunner PM, Conrad C, Vender R, et al. Integrated safety analysis of treatment-emergent eczematous reactions in patients with moderate-to-severe psoriasis treated with ixekizumab, etanercept and ustekinumab. Br J Dermatol. 2021;185(4):865-867. doi:10.1111/ bjd.20527

93. Hueber W, Sands BE, Lewitzky S, et al. Secukinumab, a human anti-IL-17A monoclonal antibody, for moderate to severe Crohn's disease: unexpected results of a randomised, double-blind placebo-controlled trial. Gut. 2012;61(12):1693-1700. doi:10.1136/ gutjnl-2011-301668

94. Targan SR, Feagan B, Vermeire S, et al. A randomized, doubleblind, placebo-controlled phase 2 study of brodalumab in patients with moderate-to-severe Crohn's disease. Am J Gastroenterol. 2016;111(11):1599-1607. doi:10.1038/ajg.2016.298

95. Yamada A, Wang J, Komaki Y, Komaki F, Micic D, Sakuraba A. Systematic review with meta-analysis: risk of new onset IBD with the use of anti-interleukin-17 agents. Aliment Pharmacol Ther. 2019;50(4):373-385. doi:10.1111/apt.15397

96. Hohenberger M, Cardwell LA, Oussedik E, Feldman SR. Interleukin-17 inhibition: role in psoriasis and inflammatory bowel disease. $J$ Dermatol Treat. 2017;29(1):13-18. doi:10.1080/09546634.2017.1329511 
97. Fauny M, Moulin D, D'Amico F, et al. Paradoxical gastrointestinal effects of interleukin-17 blockers. Ann Rheum Dis. 2020;79 (9):1132-1138. doi:10.1136/annrheumdis-2020-217927

98. Penso L, Bergqvist C, Meyer A, et al. Risk of inflammatory bowel disease in patients with psoriasis, psoriatic arthritis and ankylosing spondylitis initiating interleukin 17 inhibitors: a nationwide population-based study using the French national health data system. Arthritis Rheumatol. 2021. doi:10.1002/ art. 41923

99. Kuwana M, Miyagawa $\mathrm{H}$, Hara $\mathrm{H}$, et al. Characteristics of anti-IL-17/23 biologics-induced interstitial pneumonia in patients with psoriasis. PLoS One. 2021;16(1):e0245284. doi:10.1371/ journal.pone. 0245284
100. Matsumoto Y, Abe N, Tobita R, et al. The risk of interstitial lung disease during biological treatment in Japanese patients with psoriasis. Clin Exp Dermatol. 2020;45(7):853-858. doi:10.1111/ ced. 14259

101. Curtis JR, Sarsour K, Napalkov P, Costa LA, Schulman KL. Incidence and complications of interstitial lung disease in users of tocilizumab, rituximab, Abatacept and anti-tumor necrosis factor $\alpha$ agents, a retrospective cohort study. Arthritis Red Ther. 2015;17(1):319. doi:10.1186/s13075-015-0835-7

\section{Publish your work in this journal}

Psoriasis: Targets and Therapy is international, peer-reviewed, open access journal focusing on psoriasis, nail psoriasis, psoriatic arthritis and related conditions, identification of therapeutic targets and the optimal use of integrated treatment interventions to achieve improved outcomes and quality of life. Visit http://www.dovepress. com/testimonials.php to read real quotes from published authors. 